\title{
TRANSACTIONS DATA TESTS OF EFFICIENCY OF THE CHICAGO BOARD OPTIONS EXCHANGE*
}

\author{
Mihir BHATTACHARYA \\ The University of Michigan, Ann Arbor, MI 48109, USA
}

Received December 1981, final version received December 1982

This paper performs lower boundary condition tests based on rational pricing of call options and an implied standard deviation test based on the bid/ask prices of options. These efficiency tests attempt to closely approximate conditions in the option markets to avoid the pitfalls indicated by Phillips and Smith (1980). The tests use transactions data and account for the effects of stock and option bid/ask prices, simultaneity of stock and option prices, depth of market, execution lag and transaction costs. The small and relatively infrequent profits due to market mispricing disappear in the lower boundary tests when transaction costs are taken into account. Frequent violations of the tighter boundary conditions in the implied standard deviation test are reported, but the estimated profits cannot be unambiguously attributed to option market inefficiency.

\section{Introduction}

Tests of market efficiency have, in the past, been conducted at several levels of rigor. Those which avoid confounding joint tests of hypotheses while closely approximating the market's operational constraints are more rigorous than those that do not. Therefore, a greater probability of realizing the reported extra economic profits, if any, may be ascribed to the former category of tests. This paper describes such rigorous tests for call options traded on the Chicago Board Options Exchange (CBOE).

In testing option market efficiency, two issues are crucial: (a) simultaneity of option price and underlying stock price data, and (b) 'error free' measurement of the input parameters, notably, the variance of the underlying stock return. Further, since an option is generally bought at its ask price and sold at its bid price, one must consider the bid/ask spread in an efficiency

\footnotetext{
*This research was supported in part by a summer research grant from the Graduate School of Business Administration at the University of Michigan. I would like to acknowledge the help of my dissertation committee: James Hoag, Mark Garman, Michael Klass and especially Mark Rubinstein (chairman). Thanks also to Steve Brown, Blair Hull, Richard Rendleman, Adrian Tschoegl and the referee, Clifford Smith, for their comments; and Interactive Data Corporation for the T-bill rate data. I remain solely responsible for all errors.
} 
test. ${ }^{1}$ Otherwise, ex-post trading rules may 'systematically pick out. as undervalued, call prices from transactions initiated by orders to sell' [Phillips and Smith (1980, p. 186)]. Finally, depth of the market, that is, number of option contracts traded at a given price. is relevant to determine whether an additional trade could have been executed at that price to exploit mispricing of an option.

None of the previous work considers the option bid/ask spread or the depth of the market. Transactions costs are either ignored or dismissed as being insignificant when, in fact, they can be quite substantial. Except for Galai $(1977,1978)$ and Klemkosky and Resnick (1980) in the context of put/call parity, all previous researchers ignore the time lag in acting upon a profit opportunity indicated by a mispricing signal.

This paper tests, with modifications, the rational boundary conditions for call options developed by Merton (1973) and Galai (1978). ${ }^{2.3 .+}$ In addition. a convexity test on calls, using butterfly spreads, is performed. ${ }^{5}$ A new spreading test based on relative mispricing between calls of identical maturities but differing strike prices written on the same underlying stock, is proposed and performed. It is argued that excess profit situations may exist when the ranges of the standard deviations of the underlying stock returns implied by the bid/ask prices of the two options, that is, the $\hat{\sigma}_{\mathrm{bid}_{1}}$ to $\hat{\sigma}_{\mathrm{a}: \mathrm{k}_{\mathrm{f}}}$ range and the $\hat{\sigma}_{\text {bid }}$, to $\hat{\sigma}_{\text {ask }}$, range, do not overlap.

Transactions data for 58 CBOE option classes for 196 option trading days

'Trades which occur inside the bid ask spread are discussed later.

'Black and Scholes (1972). Galai (1977). and Finnerty (1978) test option market efficiency by identifying mispriced options using the Black -.Scholes (1973) formula. They use historical stock returns to estimate the variance of the underlying stock. For a critique of this approach, sec Bhattacharya (1980), and Boyle and Emanuel (1980). The other approach employed by Latane and Rendleman (1976). Trippi (1977), and Chiras and Manaster (1978) consists of implying the variance parameter from option prices and using it in an option valuation model to identify arbitrage opportunities. Most of the comments cited above are also applicable here. Furthermore, these variance estimates are not unique and require simultaneous stock and option price data. Thus the daily, weekly or monthly data used may not be adequate.

${ }^{3}$ While the proposed tests are free from measurement error with respect 00 and $r$, and are not dependent on the biases of any particular valuation model. they are sensitive to data problems, especially with regard to simultaneity, measurement of the option price, and depth of the market.

${ }^{4}$ Gadai (1978) initially performs the boundary condition tests for calls using daily closing prices for options and their underlying stocks. To avoid the selection bias associated with ex-post tests he allows a one-day execution lag in buying an underpriced option. To address the nonsimultaneity problem, he uses hourly data for one month on three options and allows one hour for execution lag. Rendleman and Carabini (1979) and Phillips and Smith (1980) suggest that the magnitude of the violations of the lower boundary condition documented by Galai can be attributed to his not considering the bid/ask spread on the call prices. Furthermore, in the absence of data about the depth of the market at each price it is not clear whether the mispricing signals could, in fact, have been translated into excess profits.

'I was informed of Galai's (1975) working paper which performs this test on daily closing prices on options traded between April 26, 1973 and November 30, 1973, a few months after the first draft of this paper was completed. 
ending June 2, 1977, are used in this study. ${ }^{6}$ The raw data base contained every reported bid/ask and transaction price record for each option for each day, along with the transaction volume and the last traded stock price. Each record is time stamped to the nearest second. This is the first time that such a large data base with, as will be seen later, nearly contemporaneous stock and option prices has been employed for efficiency tests of option markets.

\section{The proposed tests}

\subsection{Call boundary conditions}

Merton (1973) derived the rational lower boundary conditions for call prices with respect to their underlying stock prices. Although these are weak conditions on the call price, they are appealing because they imply hypotheses which can be tested without estimating any parameter for the stock or option return distribution. Galai (1978) derived the boundary conditions for exchange listed American calls. For these dividend 'unprotected' calls which can be exercised any time until maturity, including the last moment before the stock goes ex-dividend, the early exercise dominance condition for multiple dividends over the life of the option is

$C\left(S, K, \tau, D, \tau^{\prime}\right) \geqq \max \left(0, \max _{i}\left(S-K \mathrm{e}^{-r \tau_{i}} \sum_{j<i} D_{t_{j}} \mathrm{e}^{-r \tau_{j}}\right), S-K \mathrm{e}^{-r r}-\sum_{i=1}^{n} D_{t_{i}} \mathrm{e}^{-r \tau_{i}}\right)$,

where $C$ is the value of an unprotected American call; $S$ is the stock price; $K$ is the strike price; $r$ is the continuously compounded interest rate; $T$ is the maturity date; $t$ is the current date; $\tau=T-t$ is the time to maturity; $\tau^{\prime}$ is the vector of time to ex-dividend dates $t_{1}, t_{2}, \ldots, t_{n}$; and $D$ is the vector of dividend amounts $D_{t_{1}}, D_{t_{2}}, \ldots, D_{t_{n}}$. It is assumed that $D$ and $\tau^{\prime}$ are both known with. certainty. In words, (1) says that the value of an American call not protected for dividends is not less than the maximum of (a) the highest of the European call values for the option computed at each dividend date just before the stock goes ex-dividend, and (b) the European call value assuming that the call will be held to expiration. Eq. (1) tends to understate the American call value because it ignores the flexibility of the American option in allowing early exercise in the event of a sudden large change in the stock price [Cox and Rubinstein (1983)].

\footnotetext{
${ }^{6}$ The data base originally contained 95 option classes. In keeping with the assumption that dividend amounts and ex-dividend dates are known with certainty, stocks which paid special cash dividends or had stock dividends or stock splits were exclưded from the data. Thirty-seven option classes were thus excluded.
} 
For a call expected to be held until maturity, ${ }^{7}$

$$
C \geqq S-K \mathrm{e}^{-r \tau}-\sum_{i=1}^{n} D_{t_{i}} \mathrm{e}^{-r \tau_{i}}
$$

For a non-dividend paying stock, this collapses to

$$
C(S, K, \tau, 0)=c(S, K, \tau) \geqq \max \left(0, S-K \mathrm{e}^{-r \tau}\right),
$$

which is Merton's result that an American call with no dividends on the stock will not be exercised prior to maturity. Thus, it is effectively equivalent to an European call, $c$.

A testable hypothesis for well synchronized stock and option markets is that $\varepsilon$, defined as the right-hand side of (1) less its left hand side, is not less than zero. Similar hypotheses can be derived from (2) and (3).

In the above equations the call price is the equilibrium price. However, to buy a call, one would have to pay the ask price, which is higher than the equilibrium price. $^{8}$ Therefore, the appropriate test for, say, the European boundary condition consists of substituting $C_{\text {ask }}$ for $C$ in (2), thereby lowering the rational pricing bound.

When the stock bid/ask is also considered, the boundary condition for a call expected to be held until maturity becomes

$$
C_{\text {ask }} \geqq S_{\text {ask }}-K \mathrm{e}^{-r t}-\sum_{i=1}^{n} D_{t_{i}} \mathrm{e}^{-r \tau_{i}} .
$$

Two additional market constraints need to be met before call mispricing can be translated into arbitrage profits. First, a market maker is obliged to buy/sell only one contract at his bid/ask quote. Therefore, only when the volume of trade at the specific price where a boundary violation is observed is non-zero may one assume that an additional contract could have been traded (bought) at that price. Second, the trade initiator incurs transactions costs. ${ }^{9}$

\subsection{Tests of option spreads}

Two spreading tests will be proposed in this section: (a) the butterfly spread test, which is also a boundary condition test involving relative prices

${ }^{7}$ This result has also been derived in Smith (1976).

${ }^{8}$ Smidt (1979) attributes the premium over equilibrium price to cover market makers" informational disadvantage against an informationally motivated trader. Benston and Hagerman (1978) suggest it to be compensation for the market makers' inability to diversify their trading portfolio.

${ }^{9}$ Transaction cost magnitudes are discussed in the next section. 
of three options on the same underlying stock; and (b) the vertical spread between two options on the same stock based on their implied standard deviations.

Option spreading strategies are attractive because they do not involve trading in any other type of security, possibly on another exchange. Consequently, transactions costs are low to the members of the option exchange. Spreading also avoids the difficulties associated with lags in information flow from other exchanges and in execution of orders placed on other exchanges.

\subsubsection{Call convexity condition}

Call prices are convex in the striking price for identical maturity options on the same underlying stock. That is,

$$
C\left(S, K_{2}, \tau\right) \leqq q C\left(S, K_{1}, \tau\right)+(1-q) C\left(S, K_{3}, \tau\right),
$$

where $q$ is defined by $K_{2}=q K_{1}+(1-q) K_{3}$ with values $0 \leqq q \leqq 1$, and $K_{1}<K_{2}<K_{3}$ are the strike prices.

Arbitrage profit can be realized due to violations of this condition through a 'butterfly spread', that is, writing calls with exercise prices $K_{1}$ and $K_{3}$ and buying the intermediate call.

Considering the bid/ask of the options, (5) becomes

$$
C_{\text {ask }}\left(K_{2}\right) \leqq q C_{\text {bid }}\left(K_{1}\right)+(1-q) C_{\text {bid }}\left(K_{3}\right) .
$$

Clearly, simultaneity of the option prices is crucial here. Although it is impossible to obtain all observations at exactly the same instant, intra-day prices on the three options within time spans when the stock price remains unchanged is sufficient. ${ }^{10}$

\subsubsection{Spread test based on implied volatility}

Consider two options of identical maturity, on the same underlying stock, but with differing exercise prices which are not far apart. Since the maturities are identical, equilibrium prices of the two options should imply the same standard deviation of stock returns. ${ }^{11}$ However, the implied standard deviations need not be exactly equal because buying and selling prices differ. Only when the range of the standard deviations implied by the bid and the

\footnotetext{
${ }^{10}$ See footnote 19 for elaboration on the time span over which the stock price is unchanged.

${ }^{1}$ This assumes that neither option is exercised prematurely. I am grateful to Cliff Smith for this point.
} 
ask prices of option 1 does not overlap the corresponding range for option 2 , that is, if $\hat{\sigma}_{\text {bid }_{1}}$ to $\hat{\sigma}_{\text {ask }_{1}}$ is disjoint from $\hat{\sigma}_{\text {bid }_{2}}$ to $\hat{\sigma}_{\text {ask }_{2}}$, and if this disjointness persists when mapped into prices, is riskless arbitrage theoretically possible. In such a case we could buy an option at its ask price, and sell an appropriate amount of the other at its bid price, and still make a profit. ${ }^{12}$

Given $S_{\text {bid }}$ and $S_{\text {ask }}$ corresponding to $C_{\text {bid }_{1}}, C_{\text {ask }}, C_{\text {bid }_{2}}$ and $C_{\text {ask }}$, we could solve for

$$
\hat{\sigma}_{\mathrm{bid}_{i}}=f\left(S_{\mathrm{bid}}, C_{\mathrm{bid}_{i}}, K_{i}, \tau, r\right)
$$

and

$$
\hat{\sigma}_{\mathrm{ask}_{i}}=f\left(S_{\mathrm{ask}}, C_{\mathrm{ask}_{z}}, K_{i}, \tau, r\right), \quad i=1,2 .
$$

Here $\hat{\sigma}$ estimate is relatively free from estimation error in that it is not exogenously specified, nor is it a (weighted) combination of the several estimates available. ${ }^{13}$ Of course, use of the $B-S$ formula to compute the implied $\sigma$ introduces a joint hypothesis about the biases of the $\mathrm{B}-\mathrm{S}$ formula. Thus our model dependent joint test seeks to establish tighter call pricing boundary constraints than those due to rational (arbitrage free) pricing of calls.

For dividend paying stocks eq. (1) will be used to compute the standard deviation ranges. This overstates the implied standard deviations. For a small sample of options Beckers (1978) reports that the differences between the implied standard deviations obtained from eq. (1) and the Cox et al. (1979) binomial option pricing model may be as high as 10 percent. Nevertheless, to reduce computational costs, the $\mathrm{B}-\mathrm{S}$ formula with escrowed dividends adjustment will be used for dividend paying stocks.

\section{Transaction costs}

Phillips and Smith (1980) documented the ranges of transaction costs individual investors, option market makers, and arbitrageurs incur when they initiate trades in either stocks or options. ${ }^{14}$ They confirm the relatively high transaction costs incurred by an individual investor, but refute the assumption of several previous researchers that market maker transaction

${ }^{12}$ For two options $m$ and $n$,

$$
\partial C_{n}^{\text {ask }} \partial \partial S_{\text {ask }}=N\left(d_{1}\right)_{n}^{\text {ask }} \text { and } \partial C_{m}^{\text {bid }} / \partial S_{\text {bid }}=N\left(d_{1}\right)_{m}^{\text {bid }} .
$$

The neutral hedge ratio for the spread consists of buying $N\left(d_{1}\right)_{m}^{\text {bid }} / N\left(d_{1}\right)_{n}^{\text {ask }}$ contracts of $n$ for each contract of $m$ sold. This assumes that returns series $S_{\mathrm{ask}}$ and $S_{\mathrm{bid}}$ are Weiner processes.

${ }^{13}$ See footnote 2 .

${ }^{14}$ For another estimate of option market makers' transaction costs, see Rendleman and Carabini (1979). 
costs are negligible. ${ }^{15}$ Clearly, the larger the transaction costs, the wider the band within which prices can fluctuate without creating arbitrage opportunities. Studies which ignore transaction costs but reject the null hypotheses of either well synchronized stock and option markets or option market efficiency may overestimate the degree of non-synchronization or market inefficiency.

This paper considers the above issues from the position of the most advantageously placed trader. For trades in options alone, the most advantageously placed trader is the option market maker; for trades involving stocks it is the arbitrageur. ${ }^{16,17}$

The higher the commission generated for a clearing firm by a market maker, the lower his transaction cost. Therefore, although the Phillips and Smith estimates (i.e., $0.50-1.00$ /option contract and \$5.00-12.50/round lot of stock incurred by an option market maker) are generally true, some high volume market makers currently pay $\$ 0.36$ /option contract and an average of about $\$ 4.50 /$ round lot of stock. Arbitrageurs' trading costs are estimated to be about $\$ 0.80$ per option contract and $\$ 1.00$ per round lot of stock. ${ }^{18}$ These lower estimates may be attributed to increased competition among clearing houses, especially from early 1980. However, in late 1976 to mid1977 , the sample period for this study, a high volume market maker's transaction costs were about $\$ 0.75 /$ contract and $\$ 8.00 /$ round lot. These estimates fall within the range estimated by Phillips and Smith and are not far from the Rendleman and Carabini (1979) estimates of $\$ 0.80 /$ contract and $\$ 9.00$ /round lot of stock. For the same period the costs for arbitrageurs who executed their own trades in the stock were between $\$ 1.50$ and $\$ 6.00$ for a round lot and $\$ 1.50-\$ 2.00$ /option contract.

The tests proposed in the previous section will accordingly be performed under three separate assumptions of transaction costs. First, to make this study comparable with those that ignore transaction costs, I will do likewise. Next, option mispricing will be considered from the position of an arbitrageur who incurs transaction costs of $\$ 1.50$ on an option contract and $\$ 2.00$ on a round lot of stock. The final case will consider mispricing from the position of an option market maker whose corresponding transaction costs are $\$ 0.75$ and $\$ 8.00$.

\footnotetext{
${ }^{15}$ For example, Galai (1977).

${ }^{16}$ It is assumed that the option market maker does not have a seat on the stock exchange, and the arbitrageur who has a seat on the stock exchange does not perform the option market making function.

${ }^{17}$ Phillips and Smith (1980) argue that the opportunity cost of a seat on the exchange contributes to the market friction induced bound around the equilibrium price of a security traded on that exchange. While consideration of the bid/ask spread partly addresses this issue (section 4), the per option contract effect of the expected future cash flows due to arbitrage activities of the seat holders which may be impounded in the price of the seat, is not addressed.

${ }^{18}$ I am grateful to Blair Hull for discussions on this issue.
} 


\section{Data}

The sample period for the study is 196 trading days from August 24, 1976 to June 12,1977 . The data consist of options transactions derived from the CBOE Market Data Report (MDR) for 706 option series on 58 underlying stocks. ${ }^{19,20}$

Not all transactions occur at the bid or ask prices. A significant percentage occur within the bid/ask spread. If information were available on whether a trade was initiated by a buy order or by a sell order, it would be possible to estimate the marginal cost of liquidity services for an option as the difference between the lowest transaction price for a buy order and the highest transaction price for a sell order, for a constant level of the stock price. ${ }^{21}$ Unfortunately, data on who initiated the order are not available. Therefore, to avoid selecting transaction prices as sell prices when they could in fact have been initiated by buy orders, or vice versa, ${ }^{22}$ the lowest bid price at which a transaction occurred is assumed to be the bid price and the highest ask price at which trade occurred is assumed to be the ask price, for the given level of stock price. Only such unambiguous prices are used in tests of hypotheses in this paper. Evidently, this causes the tests to be biased in favor

\footnotetext{
${ }^{19}$ See Bhattacharya and Rubinstein (1978) for details. Briefly, the MDR contains every reported transaction and every reported bid/ask quote for each option. The lag between a trade or a new bid/ask quote occurring on the trading floor and its being recorded in the MDR is about 5 to 45 seconds, depending on trading activity. Late and out of sequence records are identified separately and are discarded. Each record contains the date, stock symbol, strike price, expiration date, the bid/ask quote or option price and the number of contracts traded at that price, the time the trade or new quote was recorded in hours, minutes and seconds and the last traded stock price. On an average there are more than 35,000 such records per trading day. The 'consolidated' form of the data base essentially contains two kinds of records. The first is a header record for each time span during which the stock's last traded price remained constant. A sample header is shown below:
}

$\begin{array}{cccccc}\text { XRX } & 760824 & 4 & 14: 34: 23 & 14: 40: 37 & 631 / 8 \\ (1) & (2) & (3) & (4) & (5) & (6)\end{array}$

The fields are: (1) stock symbol; (2) date; (3) number of data records following this header record; (4) and (5) beginning and ending time over which the stock traded price was constant; (6) the constant stock price for the interval.

Next are data records, one for each option on the stock with any bid/ask or trading during the above interval. A sample data record is:

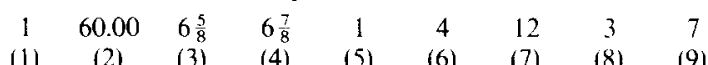

The information contained in this record is: (1) expiration month; (2) striking price; (3) lowest bid or transactions price and number of contracts traded at that price (5); (4) highest ask or transaction price and number of contracts traded at that price (6); (7) total number of contracts traded. In this case 12-4-1=7 contracts were traded at intermediate prices; and (9) the total number of raw records this data record is summarizing. This includes 3 records [see field (8)] which were bid/ask records occurring between 14:34:23 plus 3 seconds, i.e., 14:34:26 and 14:39:23.

${ }^{20}$ Table A. 2 in the appendix lists the option classes used in the study.

${ }^{21}$ See Baesel et al. (1983) for an interesting estimate of the cost to investors of the market making functions.

${ }^{22}$ This is the Phillips and Smith (1980) criticism of most previous studies. 
of the maintained hypotheses of well-synchronized option markets and option-market efficiency. Not doing so would result in a bias with indeterminate sign. ${ }^{23}$

The data do not contain the transaction price of the stock as stock trades occur. Rather, the latest price at which the stock has been traded (bought or sold) is reported only when a bid/ask change or a trade occurs in any of its options. Thus, stock prices on active option classes are recorded more frequently than those on less active option classes. Therefore, what appears as an unchanged stock price may have missed interim stock price movements up (down) and down (up) again. However, there are, on average, more than 35,000 raw observations per day among the 95 option classes, or an average of more than one observation for each option class for every trading minute. Hence, the frequency of occurrence of the foregoing phenomenon, although non-zero, is not very large.

\subsection{Imputing the stock bid/ask price}

The data do not contain the bid/ask prices of the underlying stock. Table A.1 in the appendix presents the stock price summary records for Black and Decker (BDK) for August 24, 1976. Price changes between records 1, 2, and 3 are $+\frac{1}{8},-\frac{1}{8}$. Between records $3,4,5$, and 6 price changes are $+\frac{1}{8},-\frac{1}{8}+\frac{1}{8}$. Again records 7,8 and 9 have $+\frac{1}{8},-\frac{1}{8}$ successive price changes, but at different price levels.

It can be argued that record 1 is at the bid at $19 \frac{5}{8}, 2$ is at the ask at $19 \frac{3}{4}$, and 3 at the bid again. A similar pattern holds for 3 through 6 . Note that 3 is common to two streams. Ambiguity exists, therefore, about whether it is at the bid (for the previous stream with its associated ask at $19 \frac{3}{4}$ ), or at the ask (with its bid at $19 \frac{1}{2}$ ). Such ambiguous overlaps are discarded. Thus, headers 1 through 3 and their associated data records are discarded. We therefore have two streams, each consisting of three non-overlapping reverting prices. ${ }^{24}$ Record 4 is a bid at $19 \frac{1}{2}, 5$ is an ask at $19 \frac{5}{8}, 6$ a bid at $19 \frac{1}{2}$. Similarly for 7 through 9. We can now impute the associated ask (bid) price that pertains to the data records. About 15 percent of the data records were discarded in this procedure to impute the bid/ask of the underlying stock. This may result in mispricing signals and hedge positions to be open for longer periods than they may have been on the option floor. A downward bias in the number of

\footnotetext{
${ }^{23}$ All 'consolidated' data records in which the lowest bid or transaction price was equal to the highest ask or transaction price were discarded. This condition obtains when all transactions in the options occurring within the time span of unchanging stock price are transacted at the same price, without any bid/ask price record occurring in that period. As a result, it is ambiguous whether the transactions were buy or sell transactions.

${ }^{24}$ Only non-overlapping, consecutively reverting stock price record streams of three or more records are retained for the tests.
} 
completed transactions initiated by mispricing signals and, correspondingly, an upward bias in the number of abandoned transactions also result. ${ }^{25}$

\subsection{Data screens}

All data records which had zero volume at both the bid and the ask prices of the option were discarded, so that mispricing signals would not be flagged at zero volume. Further, all options either very deep-in-the-money (where $S_{\text {bid }} / K>1.30$ ) or very deep-out-of-the-money (where $S_{\text {bid }} / K<0.75$ ) are discarded because the elasticity of prices for these options with respect to $\sigma$ is greatly different from the elasticity of those near the money. Finally, if the stock price remained unchanged for five minutes, or more, the data records were used only if they included at least one bid/ask record on the option in the 4 minutes 57 seconds interval described above. ${ }^{26}$ This requirement was intended to ensure that qualifying records would be current and would not refer to prior stock price levels.

Dividend and splits data were collected from Moody's dividend record. ${ }^{2}$ ? Treasury bill rates matching with the option maturities are used for the riskfree rate. ${ }^{28}$ The $\mathrm{T}$-bill quotations were obtained from Interactive Data Corporation.

\section{Test hypotheses and trading strategies}

(1) For the immediate exercise lower bound the hypothesis is

$$
\varepsilon_{1} \equiv S_{\text {ask }}-K-C_{\text {ask }}-b \leqq 0
$$

where $b$ is the transaction cost. The trading strategy to profit from a mispriced call which does not satisfy (9) consists of buying the underpriced call, exercising it immediately, and selling the stock thus acquired. This involves a round trip transaction in the stock (once to exercise the option and the other to sell the stock so acquired), and one way in the call (to buy the call). The net profit will be $S_{\text {bid }}-K-C_{\text {ask }}-h$, where $S_{\text {bid }}$ and $C_{\text {ask }}$ are the next available prices at non-zero trading volume, and $b$ is zero for Case I; $\$ 5.50$ for the arbitrageur (Case II) and $\$ 16.75$ for the option market maker (Case III).

\footnotetext{
${ }^{25}$ Availability of bid/ask data on the optioned stocks would eliminate these biases. Unfortunately, to the best of my knowledge, such a data base is not currently available.

${ }^{26}$ See field $(8)$ in footnote 19.

${ }^{27}$ See footnote 6 .

${ }^{28} \mathrm{~A}$ lthough lending rate may differ from the borrowing rate, we use the T-bill rate for both. Investigation of the sensitivity of the results to this assumption is deferred to later work.
} 
(2) The European boundary condition may be stated as

$$
\varepsilon_{2} \equiv S_{\text {ask }}-K \mathrm{e}^{-r \tau}-\sum_{i} D_{t_{i}} \mathrm{e}^{-r \tau_{i}}-C_{\text {ask }}-b \leqq 0 .
$$

The trading strategy to profit from a call which violates (10) consists of buying the call, shorting the stock and lending an amount equal to the sum of the present values of the exercise price and the expected dividends, and holding this portfolio till expiration. In the absence of bid/ask spreads and transaction costs, the realized profit from the hedge at expiration would be no less than the mispricing magnitude. In the presence of these market frictions, however, the magnitude and sign of the profit will depend on the stock price level at expiration. If $S>K$ at maturity, the call will be exercised and the stock thus acquired returned to the lender with dividends and interest on the dividends. In this case the net profit equals the balance cash leftover when the initial position was established, i.e., $S_{\text {bid }}-C_{\text {ask }}-K \mathrm{e}^{-r \mathrm{t}}$ $-\sum D_{t_{i}} \mathrm{e}^{-r \tau_{i}}$, plus interest thereon. Note that due to the execution lag assumed, the starting cash balance may be negative because the stock or the option prices may have moved in the interim. Therefore, call being in the money at maturity does not necessarily imply positive profits. If $S \leqq K$, the call is not exercised. Instead, the stock is bought at $S_{\text {ask }}$ and returned along with the dividend and interest thereon. In this case profit equals $\left(K-S_{\text {ask }}\right)$ plus the cash balance and interest thereon. The transactions in either case consist of buying the call and a round trip in the stock. Thus they are the same as in the previous test.

It is clear that profits realized from the above hedge are not arbitrage profits, and that it is difficult to isolate the arbitrage component of the profit attributable to market inefficiency from that solely due to the stock price drift. An alternate strategy might be to create a riskless hedge using the neutral hedge ratio together with either continuous or discrete hedge position revisions. The neutral hedge ratio has to be computed according to some valuation model. Thus, incorporating neutral hedges with interim hedge revisions transforms a rational boundary condition test into a joint test of efficiency, the valuation model, and the parameter estimates used as input for the neutral hedge ratio computations. Furthermore, revising the hedge position at intermediate points is almost certain to eliminate the arbitrage opportunity on a net of transaction cost basis. Yet another approach may be to simply analyze the mispricing signals only arguing that market frictions are negligible [Galai (1978)]. In view of the even less palatable alternatives, the initially proposed trading strategy will be employed here.

(3) The pseudo-American boundary condition may be stated as

$$
\varepsilon_{3} \equiv \max _{i}\left(S_{\text {ask }}-K \mathrm{e}^{-\boldsymbol{r} \tau_{i}}-\sum_{j<i} D_{t_{j}} \mathrm{e}^{-\boldsymbol{r} \tau_{j}}\right)-C_{\text {ask }}-b \leqq 0 .
$$


Other than the additional requirement of determining the optimality of premature exercise at each ex-dividend date, this test parallels the European boundary condition test. If the call is not exercised prematurely, despite exante indication of such a possibility and its associated arbitrage profits, the profit from the position is calculated exactly as in the previous test. If premature exercise is optimal, the profit computation is analogous except that the position is terminated at some $t_{i}$ instead of at $T$.

(4) For the call convexity test, the hypothesis is

$$
\varepsilon_{4} \equiv C_{\text {ask }}\left(K_{2}\right)-q C_{\text {bid }}\left(K_{1}\right)-(1-q) C_{\text {bid }}\left(K_{3}\right)-b \leqq 0 .
$$

If (12) does not hold, the trading strategy for arbitrage profits is to sell one contract of the intermediate call and buy $q$ and $(1-q)$ contracts for the lowest and highest exercise price calls, respectively.

When transaction costs are non-negligible, magnitudes of total transaction cost and arbitrage profit will depend on the stock price level at expiration. It may be cheaper for the spreader to reverse positions for options in-themoney at expiration than exercising them or having them exercised against him. That would be the case if the option transaction cost plus buying the option at the ask, or selling it at the bid, together costs lower than the stock transaction cost. Table 1 presents the profit positions at expiration under such conditions. For the zero transaction cost case, the arbitrage profit will at least equal the basis plus interest, that is, $A \mathrm{e}^{r \tau}$.

(5) Synchronization of relative prices of two identical maturity options with differing exercise prices on the same underlying stock requires that, for the second option, if (a) the market bid price is greater than the model bid

Table 1

Profit positions at expiration for the call convexity test for non-zero transaction costs. ${ }^{*}$

$\begin{array}{rrr}S^{*}>K_{3} & (1-q) C_{\text {bid }}^{*}\left(K_{3}\right)-C_{\text {ask }}^{*}\left(K_{2}\right)+q C_{\text {bid }}^{*}\left(K_{1}\right) & +A \mathrm{e}^{r z}-6 B \\ K_{3}>S^{*}>K_{2} & -C_{\text {ask }}^{*}\left(K_{2}\right)+q C_{\text {bid }}^{*}\left(K_{1}\right) & +A \mathrm{e}^{r z}-5 B \\ K_{2}>S^{*}>K_{1} & +q C_{\text {bid }}^{*}\left(K_{1}\right) & +A \mathrm{e}^{r t}-4 B \\ S^{*} \leqq K_{1} & & A \mathrm{e}^{r z}-3 B\end{array}$

${ }^{\mathrm{a}} A \mathrm{e}^{r \tau} \equiv\left[(1-q) C_{\mathrm{ask}}^{\mathrm{o}}\left(K_{3}\right)-C_{\text {bid }}^{\mathrm{o}}\left(K_{2}\right)+q C_{\mathrm{ask}}^{0}\left(K_{1}\right)\right] \mathrm{e}^{r \tau}$ represents the cash flow at the inception of the hedge and interest thereon. $C^{0}$ and $C^{*}$ are call prices at spread inception and at expiration, respectively. $S^{*}$ is the stock price at maturity; $K_{3}>K_{2}>K_{1}$ are the exercise prices for the identical maturity calls on the same underlying stock, and $0 \leqq q \leqq 1$ is defined by $K_{2}=q K_{1}+(1-q) K_{3} . \tau$ is time from inception of spread to maturity. $B$ is transaction cost/contract. For a market maker, it is assumed to be a $\$ 0.75 /$ contract. 
value, then the former should not also exceed its model ask value, or (b) the market ask price is less than the model ask value, then the former should not be less than its model bid value. That is,

$$
\begin{aligned}
\varepsilon_{5} & \equiv C_{\text {bid }_{2}}^{\text {market }}-C_{\text {ask }_{2}}^{\text {model }} \leqq 0 \quad \text { if } \quad C_{\text {bid }_{2}}^{\text {market }}>C_{\text {bid }_{2}}^{\text {model }}, \\
& \equiv C_{\mathbf{a s k}_{2}}^{\text {market }}-C_{\text {bid }_{2}}^{\text {model }} \geqq 0 \text { if } \quad C_{\text {ask }_{2}}^{\text {market }}<C_{\text {ask }_{2}}^{\text {model }},
\end{aligned}
$$

where

$$
\begin{aligned}
& C_{\text {bid }_{2}}^{\text {model }}=F\left(S_{\text {bid }}, K_{2}, T, r, \hat{\sigma}_{\text {bid }_{1}}\right), \\
& C_{\text {ask }_{2}}^{\text {model }}=F\left(S_{\text {ask }}, K_{2}, T, r, \hat{\sigma}_{\text {ask }_{1}}\right) ;
\end{aligned}
$$

$\hat{\sigma}_{\text {bid }}$ and $\hat{\sigma}_{\text {ask }}$ are obtained from (7) and (8), respectively, and $F$ is the BlackScholes formula with escrowed dividends.

Implied standard deviations depend critically on the $S / K$ ratio due to the non-linearity of the B-S formula in $\sigma$. Therefore, if the model value for atthe-money or out-of-the-money calls are computed by using the implied $\sigma$ from a (deep) in-the-money call, they may be overestimated, thereby possibly generating a large signal to buy the former and sell the latter. To check for this valuation model dependent phenomenon a two step procedure was used to identify mispriced option pairs. First, the implied $\sigma$ from the first option was used to compute model values for the second option in the pair. If a mispricing signal was detected from (13), the procedure was repeated with the option order reversed. That is, implied $\sigma$ from the second option was used to compute model values for the first option. If no confirmatory mispricing signal was detected in this direction, the previous signal was attributed to the valuation model (rather than to the market), and therefore discarded. The lesser of the absolute values of the two signals was taken to be the magnitude of relative mispricing for the option pair. Each call in the pair was tested for the possibility of premature exercise using the Roll (1977) condition for premature exercise. If either call violated this condition, the pair was discarded from further consideration. ${ }^{29}$ Options of maturities of three weeks or less were not considered because the call values for such options are insensitive to $\sigma$ [Trippi (1977)]. When ex-dividend dates occur close to option maturity dates the psuedo-American option pricing formula is not a good approximation for an American option [Cox and Rubinstein (1983) and Galai (1977)]. Consequently, options with ex-dividend dates within three days of maturity date were excluded from the sample.

The trading strategy to exploit relative mispricing of options, in this case,

\footnotetext{
${ }^{29}$ While the Roll test is an attempt to ensure that the options in each pair have identical maturities, this outcome is not guaranteed. Unanticipated dividend or large stock price changes may lead to premature exercise.
} 
consists of vertical spreads, either bearish or bullish. ${ }^{30}$ The position hedge is the inverse of the neutral hedge ratios for the two options. ${ }^{31}$ To compute the position hedge the $\mathrm{B}-\mathrm{S}$ formula and the implied variances from the underpriced call will be employed. Since the hedge ratios will change with the stock price and with time, maintaining a riskless hedge implies continuous hedge revisions and the attendant infinite transaction costs. Instead, a more realistic fortnightly revision is assumed here. In so doing, the position ceases to be riskless and its return depends on the stock price drift and the frequency of the revisions. ${ }^{32}$ Two related drawbacks of this test need to be mentioned. First, the position is at risk until the second leg is executed. Next, the position is usually implemented by multiple contract long and short positions in the respective options to approximate the theoretical position ratio. That is, if the position ratio is 2.65 it may be approximated by an $8: 3$ ratio of long and short contracts, which yields a 2.667 position ratio. Therefore, even the hedged position is not totally riskless. Furthermore, multiple contracts increase the importance of the depth of the market. We will assume fractional contract trades with linear transaction costs. Since the final results will be reported in per contract short position, this approximation will not distort the results.

\section{Impact of stock drift on test results}

From the previous section it is clear that in the presence of market friction only the immediate exercise test and the call convexity test are pure arbitrage tests. The other tests, namely, the European boundary test, the PseudoAmerican boundary test, and the vertical spread test, depend to varying extent on the stock price drift. While it is recognized that option prices depend only on the underlying stock price movement, because of the positive covariance among stock returns it is useful to report the overall market movement that occurred over the sample period for these tests. The Standard and Poor 500 index changed from 101.96 to 99.45 over the period. The range was from 107.83 to 97.15 . There were exactly equal numbers of positive and negative daily returns in the period. For the two maturity series in the period, namely, Oct--Jan.-April and Nov.-Feb.-May, the S\&P index values were

$\begin{array}{llll}\text { Expiration date } & \text { S\&P index } & \text { Expiration date } & \text { S\&P index } \\ 10 / 15 / 76 & 100.88 & 11 / 19 / 76 & 101.89 \\ 01 / 20 / 77 & 102.97 & 02 / 18 / 77 & 100.49 \\ 04 / 15 / 77 & 101.04 & 05 / 20 / 77 & 99.45\end{array}$

\footnotetext{
${ }^{30} \mathrm{~A}$ bearish (bullish) vertical spread is one in which the lower exercise price call is bought (written) and the other written (bought). Both options have the same maturity and are for the same underlying stock.

${ }^{31}$ See footnote 12.

${ }^{32}$ Changes in $\sigma$ also necessitate hedge position revision.
} 
This suggests that while stock price drift must still be taken into account when interpreting the results, the magnitude of the correction is unlikely to be very large for the rational boundary condition tests. However, for the vertical spread test, due to the infrequent hedge revisions, the impact of stock price drift is likely to be significant.

\section{Results: Boundary condition tests}

It may be useful to recall Galai's results for these tests. His data consisted of daily closing prices on stocks and their options for the 152 trading days from April 26, 1973, through November 30, 1973, covering 245 option series each with at least three days of data. His results, when the treasury bill rate was used for the risk free interest rate, are shown in panel A of table 2. Panel $B$ reports our results.

\subsection{Immediate exercise bound}

For our study 86,137 observations pertaining to 706 option series met all the screening conditions described earlier. The 1,120 mispricing signals for this test under zero transaction cost assumption amounted to $1.30 \%$ of the sample size compared to Galai's $1.72 \%$. They represented 154 different option series. The signal magnitudes ranged from $\$ 6.25$ to $\$ 50.00$ per contract, with a median of $\$ 12.57 /$ contract and an average of $\$ 12.03 /$ contract contrasting with Galai's average of $\$ 35.00$ /contract. About $78 \%$ of the signals were $\$ 12.50$ or less per contract while only 18 signals exceed $\$ 25$ per contract. Interestingly, $97 \%$ of the signals were for options with less than 90 calendar days to maturity including $42 \%$, which were one week or less from maturity. No clear pattern emerged from the stock to strike price ratio associated with the signals nor by option class or by day of the week. The frequency of signals when standardized by trading volume did not increase nor decrease significantly with time, measured weekly and monthly. This suggests leveling off of the 'learning curve' claimed by traders during the CBOE's early days.

The first leg of the trading strategy for this test consists of buying the call at the next available price with reported non-zero volume. In about $29 \%$ of the instances, price changes eliminated the profit signals before the first leg could be executed. Sixty percent of the 759 executed hedges were profitable, another $24 \%$ were even, that is, yielded zero profits while the balance were unprofitable. The average profit per executed hedge was $\$ 4.91 /$ contract.

Table 3 reports the distribution of mispricing signals and realized profits or losses from the executed hedges for the no transaction cost case. When the arbitrageur transaction cost of $\$ 5.50$ is considered, the average loss is $\$ 0.59$ /contract. For the case of market maker with a transaction cost of $\$ 16.75$ round trip, there were 146 signals which exceeded this transaction 
Table 2

Comparison of results: Summary. Panel $A$ : Galai (1978, table 1), $r_{F}=$ T-bill, zero transaction costs, no bid/ask spreads; panel $B$ : this study, $r_{F}=\mathrm{T}$-bill.

\begin{tabular}{|c|c|c|c|}
\hline & $\begin{array}{l}\text { Immediate } \\
\text { exercise }^{a, d}\end{array}$ & $\begin{array}{l}\text { European } \\
\text { lower bound }^{\text {b.d }}\end{array}$ & $\begin{array}{l}\text { Pseudo-American } \\
\text { lower bound }{ }^{c . d}\end{array}$ \\
\hline \multicolumn{4}{|l|}{ (A) } \\
\hline Sample size & 16,327 & 16,327 & 16.327 \\
\hline Violation frequency & 281 & 482 & 107 \\
\hline $\begin{array}{l}\text { Average violation } \\
\text { per contract }\end{array}$ & $\$ 35.00$ & $\$ 36.30$ & $\$ 41.70$ \\
\hline \multicolumn{4}{|l|}{ (B) } \\
\hline Sample size & 86,137 & 54,735 & 32,432 \\
\hline $\begin{array}{l}\text { Mispricing frequency } \\
\text { Average mispricing }\end{array}$ & 1.120 & $1.304^{e}$ & $.442^{f}$ \\
\hline per contract & $\$ 12.57$ & $\$ 9.88^{8}$ & $\$ 10.85^{g}$ \\
\hline $\begin{array}{l}\text { Number of positions } \\
\text { executed }\end{array}$ & 759 & 670 & 139 \\
\hline \multicolumn{4}{|l|}{ Average profit per } \\
\hline contract: Case $\mathrm{I}^{\mathrm{i}}$ & $\$ 4.91$ & $\$ 5.17$ & $\$ 8.20$ \\
\hline Case II $^{\mathrm{i}, \mathrm{j}}$ & -0.59 & -6.98 & -8.26 \\
\hline Case $I I^{\mathbf{i}, \mathbf{j}}$ & -7.00 & -13.14 & -8.63 \\
\hline
\end{tabular}

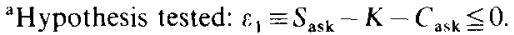

"Hypothesis tested: $\varepsilon_{2} \equiv S_{\text {ask }}-K \mathrm{e}^{-r \mathrm{rt}}-\sum D_{t_{1}} \mathrm{e}^{-r r_{1}}-C_{\text {ask }} \leqq 0$.

${ }^{\mathrm{c}}$ Hypothesis tested: $\varepsilon_{3} \equiv \max _{i}\left(S_{\text {ask }}-K \mathrm{e}^{-{ }_{r \tau_{i}}}-\sum_{j<i} D_{t_{i}} \mathrm{e}^{-r \tau_{j}}\right)-C_{\text {ask }} \leqq 0$.

${ }^{d} C_{\text {ask }}$ and $S_{\text {ask }}$ represent the ask prices of the call and the underlying stock, respectively; $K$ the exercise price; $\tau$ the time to maturity; $r$ the riskless rate; $D$ the dividend amount; $t$ the ex-dividend date; and $\tau_{j}$ the time to ex-dividend date $j$.

"Counting one violation per option series per day. If all violations are counted, there were 2,823 additional violations.

'Similarly, there were 293 additional violations.

${ }^{8}$ Based on the violations reported in the row above.

${ }^{\mathrm{h}} \mathrm{See}$ footnote $\mathrm{g}$. The others could not be executed within the same day, or price changes eliminated the signal before it could be executed. See tables 3,4 and 5 for details.

iCase I is zero transaction costs trader; Case II represents an arbitrageur: and Case III an option market maker.

${ }^{\mathrm{j} C o u n t i n g}$ only those cases where the mispricing signals exceed the transaction cost.

cost. The average loss per executed hedge was $\$ 7.00 /$ contract net of transaction cost. ${ }^{33}$

Thus, only the zero transaction cost case displayed some evidence of arbitrage profits. The rule preventing shorting a stock on the downtick cannot explain away the cases where the mispricing signal is greater than $\frac{1}{8}$

\footnotetext{
${ }^{33}$ Forty-four of the signals were eliminated by price changes prior to execution. The 70 profitable hedges averaged $\$ 1.29$ /contract while the 32 others resulted in an average loss of $\$ 25.15 /$ contract net of transaction costs.
} 
Table 3

Distribution of mispricing signals and realized profits and losses for the immediate exercise test with zero transaction costs. ${ }^{a}$

\begin{tabular}{|c|c|c|c|c|c|}
\hline \multirow{2}{*}{$\begin{array}{l}\text { Realized } \\
\text { profit/loss } \\
\text { magnitude }\end{array}$} & \multicolumn{5}{|c|}{$\begin{array}{l}\text { Frequency and magnitude of mispricing signals in } \\
\$ / \text { contract }\end{array}$} \\
\hline & $0.01-6.25$ & $6.26-12.50$ & $12.51-25.00$ & $>25.00$ & Total \\
\hline \multicolumn{6}{|c|}{ Losses in $\$ /$ contract } \\
\hline$>25.00$ & 1 & 9 & - & 1 & 11 \\
\hline $12.51-25.00$ & 3 & 20 & 5 & 1 & 29 \\
\hline $6.26-12.50$ & 13 & 41 & 5 & 1 & 60 \\
\hline $0.01-6.25$ & 11 & 5 & 2 & - & 18 \\
\hline \multicolumn{6}{|l|}{ Subtotal loss } \\
\hline frequency & 28 & 75 & 12 & 3 & 118 \\
\hline Even & 41 & 125 & 16 & 1 & 183 \\
\hline \multicolumn{6}{|c|}{ Profits in $\$ /$ contract } \\
\hline $0.01-6.25$ & 74 & 32 & 8 & -.. & 114 \\
\hline $6.26-12.50$ & 48 & 185 & 23 & 4 & 260 \\
\hline $12.51-25.00$ & 11 & 36 & 28 & 1 & 76 \\
\hline$>25.00$ & - & 2 & 3 & 3 & 8 \\
\hline $\begin{array}{l}\text { Subtotal profit } \\
\text { frequency }\end{array}$ & 133 & 255 & 62 & 8 & 458 \\
\hline Total executed & 202 & 455 & 90 & 12 & 759 \\
\hline Unexecuted ${ }^{b}$ & 81 & 236 & 38 & 6 & 361 \\
\hline Total & 283 & 691 & 128 & 18 & 1120 \\
\hline
\end{tabular}

aHypothesis being tested is: $\varepsilon_{1} \equiv S_{\text {ask }}-K-C_{\text {ask }} \leqq 0$, where $C_{\text {ask }}$ and $S_{\text {ask }}$ are the ask prices of the call and the underlying stock, and $K$ is the exercise price of the call. The sample size is 54,735 .

${ }^{b}$ Unable to execute within the same day the mispricing signal occurred.

point. A plausible alternate explanation for the existence of mispricing signals may lie in the differential transaction costs faced by participants. Recall that more than $42 \%$ of the signals had one week or less to maturity. If these mostly deep-in-the-money options were held by investors, they may have sold the calls at a discount so as to avoid having to exercise them and incur a round trip transaction cost in the stock. For the more realistic cases which considered transaction costs, no evidence contrary to option market efficiency was found, given the data and the trading strategy.

\subsection{The European lower bound}

In the absence of interim hedge position revisions and in the presence of market frictions and an execution lag, the profit from the hedged position created to exploit a violation of this bound will depend on the stock price at maturity. Therefore, to document this profit at maturity, as opposed to 
documenting mispricing at inception of the hedge, only those option series with expiration within the sample period were considered for this test. ${ }^{34}$ When multiple intra-day violations existed for the same series, the first violation per option series per day was singled out for further analysis.

There were 1,304 violations of this bound, or about $2.38 \%$ of the sample size of 54,735 , for the zero transaction cost case. When the multiple intra-day violations were considered the frequency rose to $7.56 \%$ of the sample size. The average mispricing signal magnitude was $\$ 9.88 /$ contract with a median of $\$ 7.12 /$ contract. This compares with Galai's frequency of $2.95 \%$ and average magnitude of $\$ 36.30$ /contract (see tables 2 and 4 ).

Table 4

Distribution of mispricing signals and realized profits and losses for the European boundary test with zero transaction costs.

\begin{tabular}{|c|c|c|c|c|c|}
\hline $\begin{array}{l}\text { Realized } \\
\text { profit/loss } \\
\text { magnitude }\end{array}$ & \multicolumn{5}{|c|}{$\begin{array}{l}\text { Frequency and magnitude of mispricing signals in } \\
\text { Sicontract }\end{array}$} \\
\hline \multicolumn{6}{|c|}{ Losses in Scontract } \\
\hline$>2500$ & 29 & 22 & 10 & 2 & 63 \\
\hline $12.51-25.00$ & 61 & 31 & 14 & 6 & 112 \\
\hline $6.26-12.50$ & 110 & 9 & 25 & 4 & 148 \\
\hline $0.01-6.25$ & 27 & 74 & 22 & 2 & 125 \\
\hline \multicolumn{6}{|l|}{ Subtotal loss } \\
\hline frequency & 227 & 136 & 71 & 14 & 448 \\
\hline Even & - & 4 & 2 & 1 & 7 \\
\hline \multicolumn{6}{|c|}{ Profits in $\$$ /contract } \\
\hline $0.01-6.25$ & 46 & 7 & 52 & 6 & 111 \\
\hline $6.26 \cdot 12.50$ & 2 & 14 & 26 & 4 & 46 \\
\hline $12.51-25.00$ & 9 & 2 & 1.3 & 7 & 31 \\
\hline$>25.00$ & 3 & 6 & 6 & 12 & 27 \\
\hline \multicolumn{6}{|l|}{ Subtotal profit } \\
\hline frequency & 60 & 29 & 97 & 29 & 215 \\
\hline Total executed & 287 & 169 & 170 & 44 & 670 \\
\hline Unexecuted $^{\mathrm{t}}$ & 210 & 106 & 107 & 33 & 456 \\
\hline Signal reversal ${ }^{\circ}$ & 86 & 56 & 31 & 5 & 178 \\
\hline Total & 583 & 331 & 308 & 82 & 1,304 \\
\hline \multicolumn{6}{|c|}{$\begin{array}{l}\text { "Hypothesis being tested is: } \varepsilon_{2} \equiv S_{\text {ask }}-K \mathrm{c}-{ }^{r}-\sum_{i} D_{t_{i}} \mathrm{c} \\
\text { and } S_{\text {ask }} \text { are the ask prices of the call and the underlying stock, respectively; } K \text { is } \\
\text { the exercise price; } \tau \text { is the time to maturity; } r \text { is the riskless rate; } D \text { is the dividend } \\
\text { amount; } t \text { is the ex-dividend date; and } \tau_{j} \text { is the time to ex-dividend date } j \text {. The } \\
\text { sample size is } 54,735 \text {. } \\
\text { "Unable to execute within the same day the mispricing signal occurred. } \\
\text { 'Signal disappeared due to price correction before the first leg of the trading } \\
\text { strategy could be executed }\end{array}$} \\
\hline
\end{tabular}

${ }^{34}$ Without this requirement the sample size would have remained at 86,137 analogous 10 Galai's identical samples for all tests. The latter approach is adequate only if bid/ask spreads and transaction costs are absent. In which case, effectively, only the mispricing signal is being studied without and with an execution lag. 
Slightly more than half of the 1,304 signals could be executed within the same trading day, and resulted in losses twice as often as profits. The average profit was $\$ 5.17$ excluding transaction costs. When a strategy of trying to execute mispricing signals in excess of transaction costs was adopted, the resulting executed positions averaged losses of $\$ 6.98$ and $\$ 13.14$ net of transaction costs for the arbitrageur and the option market maker, respectively.

Here again only the zero transaction cost case yielded profits on the average, although loss making positions were twice as frequent as profitable positions.

\subsection{The pseudo-American lower bound}

Since the pseudo-American lower bound is identical to the European lower bound for options with no intervening dividends until maturity, the sample for this test was a subset of the sample for the European lower bound test. Thus there were 32,432 observations each with at least one dividend to maturity, and all observations pertained to option series maturing within the sample period. The results were essentially similar to those for the European bound, and are reported in tables 2 and 5. The frequency of violations was $1.36 \%$ of sample size with average magnitude $\$ 10.85 /$ contract and a median of $\$ 8.77 /$ contract. There were an additional 293 (or $0.90 \%$ of sample size) multiple intra-day violations.

Two-thirds of the 442 signals could not be executed either due to prices changing prior to execution or due to the same day execution constraint imposed. Losses were about two and a half times as frequent as profits. Again the average profit of $\$ 8.20 /$ contract for the no transaction case changed to losses of $\$ 8.26$ and $\$ 8.63 /$ contract net of transaction costs for Cases II and III, respectively.

\subsection{Call convexity test}

Only one violation of the call convexity test was found among the 1,006 triplets of options with identical maturity, written on the same underlying stock. For the no transaction case, the mispricing magnitude was $\$ 6.25 /$ contract. No further analysis is warranted in view of this strong result in support of the null hypothesis.

\subsection{Vertical spread test based on implied variance}

The criteria applied to data on call pairs for inclusion in the sample were that the calls have identical maturity; have different but close exercise prices; both should have traded during a time span when their common underlying stock price was unchanged; that their bid prices be unambiguously different 
Table 5

Distribution of mispricing signals and realized profits and losses for the pseudoAmerican boundary test with zero transaction costs. ${ }^{a}$

\begin{tabular}{|c|c|c|c|c|c|}
\hline \multirow{2}{*}{$\begin{array}{l}\text { Realized } \\
\text { profit/loss } \\
\text { magnitude }\end{array}$} & \multicolumn{5}{|c|}{$\begin{array}{l}\text { Frequency and magnitude of mispricing signals in } \\
\text { S/contract }\end{array}$} \\
\hline & $0.01-6.25$ & $6.26-12.50$ & $12.51-25.00$ & $>25.00$ & Total \\
\hline \multicolumn{6}{|c|}{ Losses in $\mathrm{S} /$ contract } \\
\hline$>25.00$ & 13 & 2 & $-\ldots$ & $\ldots$ & 15 \\
\hline $12.51-25.00$ & 12 & 9 & 1 & - & 22 \\
\hline $6.26-12.50$ & 23 & 7 & 9 & & 39 \\
\hline $0.01-6.25$ & 4 & 12 & 3 & 2 & 21 \\
\hline \multicolumn{6}{|l|}{ Subtotal loss } \\
\hline frequency & 52 & 30 & 13 & 2 & 97 \\
\hline Even & - & 1 & 1 & - & 2 \\
\hline \multicolumn{6}{|c|}{ Profits in $\$$ contract } \\
\hline $0.01-6.25$ & 2 & 2 & 11 & 1 & 16 \\
\hline $6.26-12.50$ & - & - & 11 & 2 & 13 \\
\hline $12.51-25.00$ & 3 & 1 & 3 & 3 & 10 \\
\hline$>25.00$ & … & - & - & 1 & 1 \\
\hline \multicolumn{6}{|l|}{ Subtotal profit } \\
\hline frequency & 5 & 3 & 25 & 7 & 40 \\
\hline Total executed & 57 & 34 & 39 & 9 & 139 \\
\hline Unexecuted $^{\mathrm{b}}$ & 101 & 63 & 86 & 20 & 270 \\
\hline Signal reversal ${ }^{\circ}$ & 17 & 10 & 4 & 2 & 33 \\
\hline Total & 175 & 107 & 129 & 31 & 442 \\
\hline
\end{tabular}

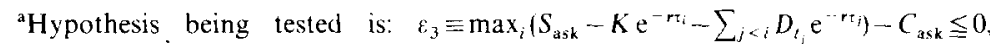
where $C_{\text {ask }}$ and $S_{\text {ask }}$ are the ask prices of the call and the underlying stock, respectively; $K$ is the exercise price; $\tau$ is the time to maturity; $r$ is the riskless rate; $D$ is the dividend amount: $t$ is the ex-dividend date and $\tau_{j}$ is the time to exdividend date $j$. The sample size is 32,432 .

"Unable to execute within the same day the mispricing signal occurred.

"Signal disappeared due to price correction before the first leg of the trading strategy could be execuled.

from their ask prices; that the time to maturity be longer than three weeks; and that no ex-dividend date should fall within three days of the maturity date. Despite these stringent screenings, more than $51 \%$ of the sample of 7,998 call pairs violated the bounds for this test for the zero transaction cost case. When only one violation per pair per day was counted, 1,444 violations (or $18 \%$ of the sample) were found. The mean mispricing magnitude was $\$ 33.84 /$ contract and the median was $\$ 14.07 /$ contract. An additional 187 violations were not considered because one of the calls of the pair could have been exercised prematurely, according to the Roll (1977) test, thereby invalidating the assumption crucial to this test that the call pair have identical maturities. The frequency and magnitudes of the violation (reported 
in table 6) are especially surprising when compared to those for the weak boundary condition tests reported above. Arbitrage profits realized from strategies suggested by the signals would imply market inefficiency, since market efficiency requires that no mechanical trading rule (even if based on a misspecified valuation model) should result in arbitrage profits.

Both legs of the spread could be executed within the day in 849 of the 1,444 'first violations of the day' analyzed further. When terminated, either at maturity or when price adjustments eliminated the mispricing, they resulted in an average profit of $\$ 102.66 /$ contract of short position in the overpriced call. The 550 profitable and the 299 loss making spreads averaged $\$ 296.80$ and $\$ 254.47$ contract of short position, respectively. The spreads were revised an average of 1.38 times over their lifetime.

Realized profits on the average being about thrice as large as the mispricing signal is very surprising and may be due to large drift component

Table 6

Distribution of mispricing signals and realized profits and losses for the implied standard deviation based vertical spread test with zero transaction costs. ${ }^{2}$

\begin{tabular}{|c|c|c|c|c|c|}
\hline \multirow{2}{*}{$\begin{array}{l}\text { Realized } \\
\text { profit/loss } \\
\text { magnitude }\end{array}$} & \multirow{2}{*}{$\begin{array}{l}\text { Frequency } \\
\$ / \text { contract } \\
0.01-12.50\end{array}$} & \multicolumn{4}{|c|}{ and magnitude of mispricing signals in } \\
\hline & & $12.51-25.00$ & $25.01-50.00$ & $>50.00$ & Total \\
\hline \multicolumn{6}{|c|}{ Losses in $\$ /$ contract } \\
\hline $\begin{array}{r}>100.00 \\
50.01-100.00\end{array}$ & $\begin{array}{l}56 \\
29\end{array}$ & $\begin{array}{l}28 \\
11\end{array}$ & $\begin{array}{r}15 \\
8\end{array}$ & $\begin{array}{r}65 \\
7\end{array}$ & $\begin{array}{r}164 \\
55\end{array}$ \\
\hline $\begin{array}{l}50.01-100.00 \\
25.01-50.00\end{array}$ & 24 & 7 & 4 & 6 & 41 \\
\hline $0.01-25.00$ & 23 & 7 & 5 & 4 & 39 \\
\hline \multicolumn{6}{|l|}{ Subtotal loss } \\
\hline frequency & 132 & 53 & 32 & 82 & 299 \\
\hline \multicolumn{6}{|c|}{ Profits in $\$$ /contract } \\
\hline $0.01-25.00$ & 19 & 11 & 3 & 9 & 42 \\
\hline $25.01-50.00$ & 27 & 8 & 4 & 3 & 42 \\
\hline $50.01-100.00$ & 41 & 23 & 6 & 5 & 75 \\
\hline$>100.00$ & 145 & 70 & 53 & 123 & 391 \\
\hline \multicolumn{6}{|l|}{ Subtotal profit } \\
\hline frequency & 232 & 112 & 66 & 140 & 550 \\
\hline Total executed & 364 & 165 & 98 & 222 & 849 \\
\hline Unexecuted $^{\mathrm{b}}$ & 266 & 147 & 73 & 59 & 545 \\
\hline Signal reversal $^{\mathfrak{c}}$ & 37 & 7 & 4 & 2 & 50 \\
\hline Total & 667 & 319 & 175 & 283 & 1,444 \\
\hline
\end{tabular}

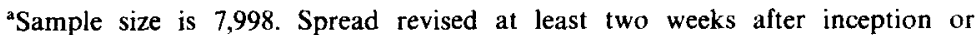
previous revision.

bUnable to execute within the same day the mispricings occurred. Includes cases where only one leg could be executed within the same day.

'Signal disappeared prior to execution of either leg. 
impact on the final outcome. Investigating this conjecture, we found that in both the signals and the executed spreads, bearish spreads were nearly five times as frequent as bullish spreads. About half of the 139 bullish spreads executed were profitable while two-thirds of the 710 bearish spreads executed were profitable. Spreads with April 1977 expirations showed that profitable bearish spreads outnumbered loss making bearish spreads by 315:43 or greater than $7: 1$ while the bullish spreads were evenly divided. The January 1977 expirations also exhibited results along the same lines although not so pronounced (198:154 bearish spreads and 22:18 bullish spreads, profitable to unprofitable ratio).

From the above we conclude that the $\mathrm{B}-\mathrm{S}$ model dependent implied variance test provides tighter boundary conditions on relative call prices. More than half the call pairs violated these tighter bounds and the average mispricing magnitude seemed large enough to overcome the transaction costs for trading in calls alone. However, the execution strategy was not an adequate approximation of a riskless position and therefore the results depended largely on the drift of the stock prices between spread creation and termination date.

Before concluding, the shortcomings of the paper need to be discussed. By working only with the widest band of the available bid/ask spread the tests have been biased in favor of the null hypotheses. Not doing so would have meant working with trades inside the bid/ask spread without unambiguously knowing whether a trade was initiated by a buy order or a sell order, resulting in ambiguous conclusions. In limiting trades to next available prices rather than at the mispricing signals themselves, the time taken to execute a hedge may be overstated. thereby biasing the tests in favor of the null hypotheses. It is conceivable that a market maker recognizes a mispriced option and trades immediately. For a researcher studying past data to do so would imply an ex-post selection bias. Finally, when imputing a bid/ask spread on the stock from its transaction prices a significant fraction of the data, about $15^{\circ}$, is discarded. Although this still retains data on the average of over 30,000 raw records per day, not imputing the bid/ask would have meant obtaining a stock bid/ask data base, which does not exist presently.

\section{Conclusions}

Four rational boundary condition tests were performed on CBOE traded calls using transactions data, considering the bid/ask of the calls and the stock, the depth of the market, execution lag and transaction costs. Small and infrequent violations of the boundaries were reported. However, the returns resulting from executed hedges were on average positive only when transaction costs are ignored. 
The B-S model dependent vertical spread test based on implied variances of simultaneously traded identical maturity call pairs uncovered frequent violations of the tighter bounds imposed by this joint test. While the proposed strategy was an inadequate approximation of a riskless spread position, the question remains whether increased transaction costs due to more frequent revisions, search costs, opportunity cost of market makers' seat and time ${ }^{35}$ are smaller than the indicated average mispricing magnitude.

\section{Appendix}

Table A.1

Stock price summary records for Black \& Decker for October 26, 1976.

\begin{tabular}{|c|c|c|c|c|}
\hline Record no. & Stock price & Begin time & End time ${ }^{\mathrm{a}}$ & $\begin{array}{l}\text { Number of } \\
\text { raw records }\end{array}$ \\
\hline 1 & $19-5 / 8$ & 9:08:37 & $10: 12: 19$ & 56 \\
\hline 2 & $19-3 / 4$ & $10: 13: 28$ & $10: 33: 20$ & 10 \\
\hline 3 & $19-5 / 8$ & $10: 40: 08$ & $10: 52: 13$ & 7 \\
\hline 4 & $19-1 / 2$ & $10: 53: 05$ & $11: 12: 27$ & 12 \\
\hline 5 & $19-5 / 8$ & $11: 23: 41$ & $11: 30: 28$ & 16 \\
\hline 6 & $19-1 / 2$ & $13: 31: 21$ & [4:07:03 & 16 \\
\hline 7 & $19-3 / 4$ & $14: 09: 13$ & 14:09:13 & 1 \\
\hline 8 & $19-5 / 8$ & $14: 31: 12$ & $14: 31: 37$ & 4 \\
\hline 9 & $19-3 / 4$ & $14: 46: 45$ & $14: 59: 50$ & 14 \\
\hline
\end{tabular}

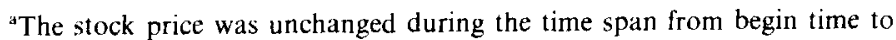
end time. Time in hours, minutes and seconds.

${ }^{b} \mathrm{Raw}$ records are either bid/ask changes or option trades in any one of the options written on the underlying stock. Fifty-six such records occurred between 9:08:37 and 10:12:19.

Table A.2

List of optioned stocks in the data.

\begin{tabular}{ll}
\hline \multicolumn{1}{c}{ Ticker symbol } & Stock name \\
\hline 1. AA & Aluminum Co. of America \\
2. AEP & American Electric Power \\
3. AHS & American Hospital Supply \\
4. AMP & AMP, Inc. \\
5. AVP & Avon Products, Inc. \\
6. BCC & Boise Cascade Corp. \\
7. BDK & Black \& Decker Mfg. Co. \\
8. BGH & Burroughs Corp. \\
9. BNI & Burlington Northern, Inc. \\
10. CBS & CBS, Inc. \\
11. CL & Colgate Palmolive
\end{tabular}

${ }^{35}$ See footnote 17. 
Table A.2 (continued)

\begin{tabular}{|c|c|}
\hline Ticker symbol & Stock name \\
\hline 12. CWE & Commonwealth Edison Co. \\
\hline 13. DAL & Delta Airlines, Inc. \\
\hline 14. FlR & Fluor Corp. \\
\hline 15. FNC & Citicorp \\
\hline 16. FNM & Federal National Mortgage Assn. \\
\hline 17. $\mathrm{GE}$ & General Electric Co. \\
\hline 18. GF & General Foods \\
\hline 19. HIA & Holiday Inns, Inc. \\
\hline 20. $\mathrm{HON}$ & Honeywell. Inc. \\
\hline 21. HR & International Harvester Co. \\
\hline 22. IBM & International Business Machines Corp. \\
\hline 23. IFF & International Flavor \& Fragrances, Inc. \\
\hline 24. IGL & International Minerals \& Chemical Corp. \\
\hline 25. IP & International Paper $\mathrm{Co}$ \\
\hline 26. ITT & International Telephone \& Telegraph Co. \\
\hline 27. JM & Johns Manville Corp. \\
\hline 28. JWC & Jim Walter Corp. \\
\hline 29. $\mathrm{KG}$ & Kresge Co. \\
\hline 30. KMG & Kerr-McGee Corp. \\
\hline 31. $\mathrm{KN}$ & Kennecott Copper Corp. \\
\hline 32. LTR & Loew's \\
\hline 33. $\mathrm{MCD}$ & McDonald's Corp. \\
\hline 34. MER & Merrill Lynch \& Co., Inc. \\
\hline 35. MGI & MGIC Investment \\
\hline 36. $\mathrm{MMM}$ & Minnesota Mining \& Mfg. \\
\hline 37. MRK & Merck \& Co.. Inc. \\
\hline 38. MTC & Monsanto Co. \\
\hline 39. NCR & NCR Corp. \\
\hline 40. NWA & Northwest Airlines, Inc. \\
\hline 41. OXY & Occidental Petroleum Corp. \\
\hline 42. PRD & Polaroid Corp. \\
\hline 43. $\mathrm{PZL}$ & Pennzoil Co. \\
\hline 44. RCA & RCA Corp. \\
\hline 45. RJR & Reynolds (R.J.) Industries, Inc. \\
\hline 46. SKY & Skyline Corp. \\
\hline 47. $S N$ & Standard Oil Co. (1N) \\
\hline 48. SO & Southern Co. \\
\hline 49. SY & Sperry Rand Corp. \\
\hline 50. TG & Texas Gulf Inc. \\
\hline 51. TSO & Tesoro Petroleum \\
\hline 52. $\mathrm{TXN}$ & Texas Instruments, Inc. \\
\hline 53. UAL & UAL, Inc. \\
\hline 54. UPJ & Upjohn Co. \\
\hline 55. UTX & United Technologies Corp. \\
\hline 56. WMB & Williams Cos. \\
\hline 57. WY & Weyerhaeuser $\mathrm{Co}$. \\
\hline 58. XRX & Xerox Corp. \\
\hline
\end{tabular}




\section{References}

Baesel, J., G. Shows and E. Thorpe, 1983, The cost of liquidity services in listed options, Journal of Finance, forthcoming.

Beckers, S., 1978, Variance prediction: An empirical study, Working paper no. 83 (Institute Business and Economic Research, University of California, Berkeley, CA).

Benston, G. and R. Hagerman, 1978, Risk volume and spread, Financial Analysts Journal, Jan.Feb., 44-59.

Bhattacharya, M., 1980, Empirical properties of the Black-Scholes formula under ideal conditions, Journal of Financial and Quantitative Analysis 15, 1081-1105.

Bhattacharya, M. and M. Rubinstein, 1978, Berkeley options transactions data base, Mimeo. (University of California, Berkeley, CA).

Black, F. and M. Scholes, 1972, The valuation of option contracts and a test of market efficiency, Journal of Finance 27, 399-417.

Black, F. and M. Scholes, 1973, The pricing of options and corporate liabilities, Journal of Political Economy 81, 637-654.

Boyle, P. and D. Emanuel, 1980, Discretely adjusted option hedges, Journal of Financial Economics 8, 259-282.

Chiras, D. and S. Manaster, 1978. The information content of option prices and a test of market efficiency, Journal of Financial Economics 6, 213-234

Cox, J. and M. Rubinstein, 1983, Option markets (Prentice-Hall, Englewood Cliffs, NJ) forthcoming.

Cox, J., S. Ross and M. Rubinstein, 1979, Option pricing: A simplified approach, Journal of Financial Economics 7, 229-263.

Finnerty, J., 1978, The Chicago Board Options Exchange and market efficiency, Journal of Financial and Quantitative Analysis 13, 29-38.

Galai, D., 1975, Tests of efficiency of the Chicago Board Options Exchange (CBOE) - - The 'general form' tests, Working paper (The Hebrew University, Jerusalem).

Galai, D., 1977, Tests of market efficiency of the Chicago Board Options Exchange, Journal of Business $50,167-197$.

Galai, D., 1978, Empirical tests of boundary conditions for CBOE options, Journal of Financial Economics 6, 187-211.

Klemkosky, R. and B. Resnick, 1980, An ex ante analysis of put-call parity, Journal of Financial Economics 8, 363-378.

Latane, H. and R. Rendleman, 1976, Standard deviation of stock price ratios implied by option prices, Journal of Finance 31, 369-381.

Merton, R., 1973, Theory of rational option pricing, Bell Journal of Economics and Management Science 4, 141-183.

Phillips, S. and C. Smith, Jr., 1980, Trading costs for listed options: The implications for market efficiency, Journal of Financial Economics 8, 179-201

Rendleman, R. and C. Carabini, 1979, A re-examination of the efficient markets hypothesis: A review of recent empirical work, Unpublished manuscript (DePaul University, Chicago, IL).

Roll, R., 1977, An analytic valuation formula for unprotected call options on stocks with known dividends, Journal of Financial Economics 5, 251-258.

Smidt, S., 1979, Continuous versus intermittent trading on auction markets, Journal of Financial and Quantitative Analysis 14, 837-866.

Smith, Jr., C., 1976, Option pricing: A review, Journal of Financial Economics 3, 3-51.

Trippi, R., 1977, A test of option market efficiency using a random-walk valuation model, Journal of Economics and Business 29, 93-98. 